J. Lake Sci. (湖泊科学), 2019, 31(5): 1239-1247

DOI 10. 18307/2019. 0518

(c) 2019 by Journal of Lake Sciences

\title{
水体氮、磷营养盐水平对蓝藻优势形成的影响”
}

\author{
许 海 $^{1}$, 陈 洁 $^{1,2}$, 朱广伟 $^{1 * *}$, 秦伯强 ${ }^{1}$, 张运林 $^{1}$ \\ (1:中国科学院南京地理与湖泊研究所湖泊与环境国家重点实验室,南京 210008) \\ (2:江南大学环境与土木工程学院,无锡 214122)
}

\begin{abstract}
摘 要: 以江苏省南京市富营养化程度不同的清溪、护城河、玄武湖、月牙湖、琵琶湖和前湖为研究对象, 调查各水体浮游 植物的群落特征和优势种, 并结合藻类生长潜力试验, 探究不同氮、磷营养水平的自然水体对铜绿微囊藻 (Microcystis aeruginosa) 和斜生栅藻 (Scenedesmus obliquus) 生长与竞争的影响. 野外调查发现不同营养水平水体浮游植物优势种不同, 按水体富营养化程度从高到底依次以绿藻、蓝藻、硅藻和隐藻分别占优势. 单一藻种培养时, 铜绿微囊藻在清溪、护城河 和玄武湖水体中生长均较好, 而斜生栅藻仅在高氮、磷浓度的清溪和护城河水体中有较大生长量, 说明斜生栅藻对氮、磷 的需求高于铜绿微囊藻; 两种藻共培养时, 清溪水体中斜生栅藻占优势, 护城河和玄武湖水体中铜绿微囊藻占优势, 但其 他水体中两种藻均不能生长, 说明氮、磷浓度过高或过低都不利于蓝藻形成优势. 对低营养水平的玄武湖、琵琶湖、月牙 湖和前湖水体进行氮、磷加富后, 两种藻均能较好地生长, 且各组没有显著差异, 说明藻类在这些水体中生长受到氮、磷 的限制, 氮、磷浓度升高会增加水华发生的风险. 本研究将野外调查和藻类生长潜力实验相结合, 深人探究了蓝藻优势形 成与水体氮、磷营养水平的关系, 揭示了蓝藻水华是湖泊富营养化发展到特定阶段的产物, 水体氮、磷浓度过高或过低均 不易产生蓝藻优势.
\end{abstract}

关键词: 浮游植物; 优势种; 蓝藻; 藻类生长潜力实验; 营养盐限制

\section{Effect of concentrations of phosphorus and nitrogen on the dominance of cyanobacteria}

\author{
XU Hai ${ }^{1}$, CHEN Jie ${ }^{1,2}$, ZHU Guangwei ${ }^{1 * *}$, QIN Boqiang ${ }^{1} \&$ ZHANG Yunlin $^{1}$ \\ (1: State Key Laboratory of Lake Science and Environment, Nanjing Institute of Geography and Limnology, Chinese Academy \\ of Sciences, Nanjing 210008, P.R. China) \\ (2: School of Environment and Civil Engineering, Jiangnan University, Wuxi 214122, P.R.China)
}

\begin{abstract}
Six lakes (rivers) in Nanjing, Jiangsu Province, with different nutrient levels, were investigated for the phytoplankton community and dominant species. They were Qingxi River, Hucheng River, Xuanwu Lake, Yueya Lake, Pipa Lake and Qianhu Lake. At the same time, algae growth potential tests (AGP tests) were conducted to examine the growth and competition characteristics of Microcystis aeruginosa and Scenedesmus obliquus in different water bodies. Field investigation found that water bodies with different nitrogen $(\mathrm{N})$ and phosphorus ( P ) concentration have different dominant species. According to nutrient level of water bodies, Chlorophyta, Cyanophyta, Bacillariophyta and Cryptophyta appeared in sequence as dominant species. When cultured with a single algae species, M. aeruginosa grew better in water bodies collected from Qingxi River, Hucheng River and Xuanwu Lake; while $S$. obliquus only showed a large maximal cell density when cultured in water with high nutrient levels collected from Qingxi River and Hucheng River. It indicated that $\mathrm{N}$ and $\mathrm{P}$ demand of $S$. obliquus may be higher than that of M. aeruginosa. When cultured with multi-species, S. obliquus dominated in water body of Qingxi River, and M. aeruginosa dominated in water body of Xuanwu Lake. But the algae could not grow in other water bodies. It indicated that cyanobacteria will not be dominant phytoplankton in waters with too high or too low $\mathrm{N}$ and P concentrations. N and P enrichment experiments were conducted using water from Xuanwu
\end{abstract}

* 国家自然科学基金项目 (41573076)、中国科学院前沿科学重点研究项目 (QYZDJ-SSW-DQC008)、国家水体污染控 制与治理科技重大专项 (2017ZX07203-001) 和中国科学院南京地理与湖泊研究所 “一三五” 战略发展规划项目 ( NIGLAS2017GH04) 联合资助. 2018-12-15 收稿; 2019-04-08 收修改稿. 许海 (1978 ) , 男, 博士, 副研究员; E-mail:hxu@ niglas.ac.cn.

** 通信作者;E-mail:gwzhu@ niglas.ac.cn. 
Lake, Hucheng River, Yueya Lake and Qianhu Lake, whitch had low N and P levels. The concentrations of N and P would influence the growth of algae, while the concentrations increased, the risk of blooms would increase. Through field investigation and AGP text to explore the relationship between the formation of cyanobacteria and the level of nutrient in water, which provided a scientific basis for revealing the cyanobacteria bloom is the product of eutrophication lake to a certain stage. It is difficult to produce cyanobacteria bloom with too low or too high $\mathrm{N}$ and $\mathrm{P}$ concentrations.

Keywords: Phytoplankton; dominate algae species; cyanobacteria; algae growth potential tests; nutrient limination

目前, 水体富营养化已经成为一个世界性的环境问题 ${ }^{[1]}$. 随着水体富营养化的发展, 许多水体的浮游植 物群落逐渐从以硅藻和绿藻为优势演替为以蓝藻为优势 ${ }^{[2-5]}$, 其中最常见的优势蓝藻有微囊藻 ( Microcystis spp.)、鱼腥藻 (Anabaena spp.)、颤藻 (Oscillatoria spp.)、束丝藻 (Aphanizomenon spp.) 等 ${ }^{[6-7]}$. 蓝藻形成优势 后, 会漂浮在水面或堆积在岸边, 高温分解时会散发恶臭, 部分蓝藻甚至还会产生藻毒素, 毒害水生生物 ${ }^{\left[{ }^{[}\right]}$. 如果大量蓝藻水华聚集在水源地取水口附近, 还有可能引起水源地的水质恶化, 从而危及供水安全. 近年, 太湖、巢湖和滇池频频暴发大规模蓝藻水华. 2007 年 5 月发生在无锡太湖贡湖水厂的 “水危机事件” 集中反 映了蓝藻水华灾害的严重性 ${ }^{[9]}$.

蓝藻优势形成是其自身生理特征以及营养盐、温度、光照、水文和气象条件等诸多因素综合作用的结 果 ${ }^{[10-16]}$. 其中, 氮和磷作为藻类生长的物质基础, 其浓度的升高被普遍认为是蓝藻水华发生的根本原因 ${ }^{[1]}$. 国际上一般认为总氮超过 $0.2 \mathrm{mg} / \mathrm{L}$ 、总磷超过 $0.02 \mathrm{mg} / \mathrm{L}$ 时, 水体就处于富营养化状态 ${ }^{[17]}$. 淡水湖泊中磷通 常被认为是蓝藻水华发生的主要限制因子 ${ }^{[18]}$. 伴随着湖泊富营养化, 尤其是水体中磷浓度的增加, 通常会 导致水体中浮游植物的种群组成朝着形成水华的蓝藻演替 ${ }^{[19]}$. Downing 等 ${ }^{[20]}$ 分析了 99 个温带湖泊磷浓度 与蓝藻优势形成的关系, 发现磷浓度 $<30 \mu \mathrm{g} / \mathrm{L}$ 时, 蓝藻优势形成的风险 $<10 \%$; 当磷浓度介于 $30 \sim 70 \mu \mathrm{g} / \mathrm{L}$ 时, 风险增至 $40 \%$; 当磷浓度接近 $100 \mu \mathrm{g} / \mathrm{L}$ 时, 风险高达 $80 \%$ 左右. 加拿大科学家 Smith 调查世界范围内 17 个湖泊, 发现水华蓝藻容易在 N/P 质量比小于 29 的湖泊中形成优势, 这一结论形成了后来的 “ N/P 比假 说”, 即低 $N / P$ 比有利于蓝藻优势形成 ${ }^{[21]}$. 但也有研究表明, 水体 N/P 比较高时也会形成蓝藻水华, 因此认 为, 较低的 $N / P$ 比不是蓝藻水华形成的条件, 而是蓝藻水华产生的结果 ${ }^{[22]}$.

由于许多富营养化湖泊中浮游植物主要以蓝藻为优势 ${ }^{[23-24]}$, 因此, 蓝藻优势常常被认为是富营养化进 程的最终状态. 但许多氮、磷浓度较低的水体, 也时常暴发蓝藻水华, 如中营养水平的千岛湖在 1998 和 1999 年曾发生大面积的蓝藻水华 ${ }^{[25]}$. 有室内模拟试验表明蓝藻生长所需的氮、磷浓度并不比绿藻高 ${ }^{[26-27]}$, 微囊 藻在低营养盐时更具竞争优势 ${ }^{[28]}$. 因此, 了解水华蓝藻形成优势是否是水体富营养化发展的必然结果将有 助于预测湖泊富营养化发展趋势, 提出合理的富营养化控制措施.

分析湖泊长时间序列监测数据是研究湖泊富营养化过程和生态变化的重要方法 ${ }^{[6,14]}$. 监测特定水体从 贫营养向富营养状态演变的过程, 对于研究浮游植物群落演替与富营养化进程的关系具有重要意义. 但自 然水体富营养化进程缓慢, 需要几十年以上的时间. 近年来受人为活动的影响, 湖泊富营养化进程明显加 快, 但很多时候缺乏对整个演变过程的监测. 通过对同一水系或水动力相似, 但富营养化程度不同的水体进 行生态调查,采取以空间换时间的办法成为研究富营养化进程引起生态变化的替代方法.

本文选取江苏省南京市富营养化程度不同的水体: 清溪、护城河、玄武湖、琵琶湖、月牙湖和前湖为研究 对象, 通过野外调查对比不同营养水平水体浮游植物优势种群, 结合室内藻类生长潜力试验 (AGP), 对比研 究不同营养水平水体对蓝藻门的铜绿微囊藻 (Microcystis aeruginosa) 和绿藻门的斜生栅藻 (Scenedesmus obliquus) 生长与竞争的影响, 验证野外观测到的水体营养水平对浮游植物优势形成的影响. 以往的研究多通 过野外调查研究浮游植物的群落动态特征 ${ }^{[2,8]}$, 或是通过室内模拟实验研究氮、磷营养盐对浮游植物生长的 影响 ${ }^{[26-33]}$ 和不同藻种间的生长竞争及优势形成的原因 ${ }^{[26-28]}$, 很少形成野外调查与室内模拟相结合的研究体 系来探究营养盐水平与浮游植物优势种的关系. 本文将两者结合, 研究氮、磷营养水平对蓝藻优势形成的影 响,这对于揭示蓝藻水华暴发机理和制定合理的水体富营养化控制策略具有重要的意义. 


\section{1 材料与方法}

\section{1 野外生态调查}

1.1.1 研究点位概况 研究区位于江苏省南京市境内, 属亚热带季风气候区, 四季分明, 年平均气温 $15^{\circ} \mathrm{C}$, 年 平均降水量 $1033 \mathrm{~mm}$, 降雨多发生在夏季. 选取污染程度不同的 6 个水体: 清溪、护城河、玄武湖、琵琶湖、月 牙湖和前湖进行生态调查. 其中清溪和护城河是南京城市内河, 水体常年处于静止状态, 主要污染源是附近 居民的生活污水. 玄武湖是南京城市湖泊, 受城市生活污水的影响, 早在 $1980 \mathrm{~s}$ 后期, 玄武湖已严重富营养 化 ${ }^{[34]}$. 1990s 初通过截污、清淤和引水冲污等系列措施, 富营养化进程得到控制, 水质得以改善, 然而, 2005 年夏季玄武湖首次大面积出现以微囊藻为主的蓝藻水华. 月牙湖紧邻紫金山, 主要受城市生活污水的污染. 琵琶湖位于中山陵风景区内的明城墙下, 受琵琶山庄餐饮污水的污染, 2005 年湖面曾出现大量蓝藻水华. 前 湖是位于紫金山脚下的天然小型湖泊,无明显的污染源,水质相对较好.

1.1.2 样品采集与处理 分别于 $4 、 8 、 10$ 月和翌年 2 月进行采样, 代表春、夏、秋、冬 4 个季节, 本文主要介绍 了夏季采样结果. 采样工作一般选择晴好天气, 利用 $1 \mathrm{~L}$ 的采水器采集表层 (距水面 $0.5 \mathrm{~m}$ ) 水样. 首先采集 1 $\mathrm{L}$ 水样, 现场加人 $1.5 \%$ 的鲁哥试剂, 用于浮游植物定性与定量分析. 另外采集表层水样 $6 \mathrm{~L}$ 带回实验室,一 部分用于氮、磷营养盐测定, 剩余水样用于藻类生长潜力试验 (AGP). 采样同时现场测定水温、透明度 (SD)、 $\mathrm{pH}$ 值、电导率 $(\mathrm{EC})$ 等指标.

1.1.3 浮游植物定性与定量分析 浮游植物定性分析用 OLYMPUS C41 型普通显微镜于 400 倍下进行鉴定, 一般鉴定到属, 种类鉴定参照《中国淡水藻类——系统、分类及生态》 ${ }^{[35]}$. 采用视野法在 OLYMPUS C41 型普 通显微镜下进行镜检计数, 吸取充分摇匀样品 $0.1 \mathrm{ml}$ 于 $0.1 \mathrm{ml}$ 计数框内计数 100 个视野, 每个样品计数两 片取平均值, 每次计数的结果与其平均值之差应不大于 $15 \%$, 如两片计数相差较大再计数一片 ${ }^{[36]}$.

1.1.4 理化指标测定方法 水体总氮 (TN) 浓度采用碱性过硫酸钾消解一紫外分光光度法测定, 总磷 (TP) 浓 度采用过硫酸钾消解一钿锑抗显色分光光度法; 溶解性反应磷 (SRP) 浓度采用钿锑抗显色分光光度法测 定; 铵态氮 $\left(\mathrm{NH}_{4}^{+}-\mathrm{N}\right)$ 浓度采用溴酚蓝法测定; 硝态氮 $\left(\mathrm{NO}_{3}^{-}-\mathrm{N}\right)$ 浓度采用酚二磺酸光度法测定; $\mathrm{pH}$ 值用 $\mathrm{pH} 2206$ 型 $\mathrm{pH}$ 计测定; 溶解氧浓度采用 RSS5100 型便携式溶解氧测定仪测定; 电导率由 HACH 型便携式电 导仪测定. 具体方法参照《湖泊生态系统观测方法》 ${ }^{[37]}$.

\section{2 藻类生长潜力试验}

1.2.1 藻种处理 试验所用蓝藻为铜绿微囊藻 (Microcystis aeruginosa), 绿藻为斜生栅藻 ( Scenedesmces obliquus), 均购自中国科学院水生生物研究所. 试验前, 藻种用 BG-11 培养基预培养 1 个月. 初期采用低光照 (1000 lx) 培养, 然后逐步提高光照强度至 $2000 \mathrm{~lx}$ (铜绿微囊藻) 和 $3500 \mathrm{~lx}$ (斜生柾藻), 温度保持在 $25 \pm$ $1{ }^{\circ} \mathrm{C}$. 试验前, 藻种需用无氮、磷的 BG-11 培养基进行 $3 \sim 5 \mathrm{~d}$ 的饥饿处理, 消耗藻体的氮和磷.

1.2.2 试验设计 将 6 个不同氮、磷营养水平的水样经 $0.45 \mu \mathrm{m}$ 的微孔滤膜过滤, 去除藻类及其他悬浮颗粒 物, 滤后水作为藻种培养液, 研究不同氮、磷营养水平滤后水体对铜绿微囊藻和斜生栅藻生长及种间竞争的 影响; 同时在氮、磷浓度相对较低的玄武湖、月牙湖、琵琶湖、前湖滤后水体中添加 $0.20 \mathrm{mg} / \mathrm{L}$ 磷酸二氢钾 (以 $\mathrm{P}$ 计) 和 $4.00 \mathrm{mg} / \mathrm{L}$ 的硝酸钾 (以 $\mathrm{N}$ 计) 作为培养液, 研究氮、磷充足的情况下, 不同水体铜绿微囊藻和斜生 栅藻生长潜力差异. 另外, 将蒸馏水中加相同浓度的氮、磷作为藻种培养液, 通过对比, 检测野外自然水体中 除氮、磷以外的其他元素是否满足藻类生长.

1.2.3 接种 取一定体积的藻种以 5000 转 $/ \mathrm{min}$ 离心, 弃掉上清液, 用 $15 \mathrm{mg} / \mathrm{L}$ 的碳酸氢钠溶液洗涤后离心, 重复 3 次, 无菌水稀释后作为藻种母液. $250 \mathrm{ml}$ 锥形瓶中加人 $100 \mathrm{ml}$ 的藻种培养液 (滤后湖水) 后进行接 种, 要求试验水样中起始的藻密度在 $5.0 \times 10^{4} \mathrm{cell} \mathrm{s} / \mathrm{ml}$ 左右 (根据藻种母液体积、滤后湖水体积以及目标起始 藻密度计算用于接种的藻种母液细胞密度). 单种培养、共培养时铜绿微囊藻和斜生栅藻的藻细胞密度 相同.

1.2.4 培养条件 培养温度为 $25 \pm 1^{\circ} \mathrm{C}$; 光照强度为 $2000 \pm 10 \mathrm{~lx}$; 光暗比为 $12 \mathrm{~h}: 12 \mathrm{~h}$. 培养期间每天按时摇动 培养瓶 $2 \sim 3$ 次.

1.2.5 藻细胞计数方法 每份样品取 $0.1 \mathrm{ml}$ 藻液于 $0.1 \mathrm{ml}$ 微藻计数板中, 于显微镜下进行多次藻细胞计数, 
取平均值, 计算指数生长期内藻种的最大细胞密度. 计数频率为每隔 1 天 1 次.

\section{3 数据处理}

利用 Microsoft Excel 、SPSS 18.0 进行试验数据的统计分析与绘图,采用 LSD 多重比较法分析实验组与对 照组间的显著性差异.

\section{2 结果与分析}

\section{1 不同自然水体的理化性质}

不同水体夏季的理化指标见表 1. 清溪河氮、磷污染最严重, $\mathrm{TN}$ 浓度为 $17.00 \mathrm{mg} / \mathrm{L}$, 以 $\mathrm{NH}_{4}^{+}-\mathrm{N}$ 为主, $\mathrm{TP}$ 浓度为 $1.29 \mathrm{mg} / \mathrm{L}$, 以 $\mathrm{SRP}$ 为主. 护城河次之, TN 浓度为 $5.23 \mathrm{mg} / \mathrm{L}$, TP 浓度为 $0.41 \mathrm{mg} / \mathrm{L}$. 其他水体氮、磷浓 度相对较低. 根据湖泊富营养化标准 ${ }^{[38]}$, 除月牙湖、前湖 SRP 浓度低于富营养化状态, 其余水体氮、磷浓度 都达到富营养水平, 清溪达到超富营养水平. 琵琶湖水体尽管氮、磷浓度不高, 但透明度较低, 主要是因为藻 类大量繁殖所致,大量藻类光合作用导致 $\mathrm{pH}$ 达到了 9.5 , 也证明了这一点.

表 1 不同水体理化性质*

Tab.1 Water quality of various water bodies

\begin{tabular}{ccccccccccc}
\hline 水体 & $\begin{array}{c}\mathrm{WT} / \\
{ }^{\circ} \mathrm{C}\end{array}$ & $\mathrm{pH}$ & $\begin{array}{c}\mathrm{EC} / \\
(\mathrm{mS} / \mathrm{cm})\end{array}$ & $\begin{array}{c}\mathrm{SD} / \\
\mathrm{m}\end{array}$ & $\begin{array}{c}\mathrm{DOC} / \\
(\mathrm{mg} / \mathrm{L})\end{array}$ & $\begin{array}{c}\mathrm{TN} / \\
(\mathrm{mg} / \mathrm{L})\end{array}$ & $\begin{array}{c}\mathrm{NH}_{4}^{+}-\mathrm{N} / \\
(\mathrm{mg} / \mathrm{L})\end{array}$ & $\begin{array}{c}\mathrm{NO}_{3}^{-}-\mathrm{N} / \\
(\mathrm{mg} / \mathrm{L})\end{array}$ & $\begin{array}{c}\mathrm{TP} / \\
(\mathrm{mg} / \mathrm{L})\end{array}$ & $\begin{array}{c}\mathrm{SRP} / \\
(\mathrm{mg} / \mathrm{L})\end{array}$ \\
\hline 清溪 & 28.50 & 7.70 & 0.59 & 0.35 & 8.38 & 17.00 & 9.27 & 0.88 & 1.29 & 1.05 \\
护城河 & 30.40 & 8.90 & 0.48 & 0.24 & 7.35 & 5.23 & 3.49 & 1.92 & 0.41 & 0.24 \\
玄武湖 & 30.00 & 8.70 & 0.24 & 0.37 & 4.04 & 1.51 & 0.53 & 0.78 & 0.07 & 0.05 \\
月牙湖 & 29.80 & 8.60 & 0.34 & 0.54 & 15.48 & 1.08 & 0.33 & 0.73 & 0.02 & 0.01 \\
琵琶湖 & 32.50 & 9.50 & 0.33 & 0.30 & 18.94 & 0.74 & 0.00 & 0.57 & 0.04 & 0.03 \\
前湖 & 31.70 & 8.70 & 0.30 & 1.00 & 5.75 & 0.29 & 0.00 & 0.29 & 0.02 & 0.02 \\
\hline
\end{tabular}

* WT 表示水温; $\mathrm{EC}$ 表示电导率; $\mathrm{SD}$ 表示透明度; $\mathrm{DOC}$ 表示可溶性有机碳浓度; $\mathrm{TN}$ 表示总氮浓度; $\mathrm{NH}_{4}^{+}-\mathrm{N}$ 表示铵态氮浓 度; $\mathrm{NO}_{3}^{-}-\mathrm{N}$ 表示硝态氮浓度; $\mathrm{TP}$ 表示总磷浓度; $\mathrm{SRP}$ 表示溶解性反应磷浓度.

\section{2 不同氮、磷营养水平自然水体的浮游植物优势种}

野外调查发现不同氮、磷营养水平水体的浮游植物优势种不同 (表 2). 其中污染最严重的清溪水体主 要优势浮游植物是绿藻门的卵囊藻 (Oocystis spp.) ; 污染相对较轻的玄武湖和琵琶湖为蓝藻门的微囊藻 ( Microcystis spp.) 占绝对优势, 同时琵琶湖内还有大量束丝藻 (Aphanizomenon spp.) 出现; 护城河和月牙湖中蓝藻 门的色球藻 (Chroococcus spp.) 和硅藻门的小环藻 (Cyclotella spp.) 占主导优势, 此外, 月牙湖还出现了大量的 平列藻 (Merismopedia spp.) ; 而营养水平最低的前湖则以隐藻门的蓝隐藻 (Chroomonas spp.) 为优势种.

表 2 不同自然水体浮游植物优势种

Tab.2 Phytoplankton dominant species in different water bodies

\begin{tabular}{|c|c|c|c|c|c|c|c|c|}
\hline & 优势种 & 拉丁学名 & 清溪 & 护城河 & 玄武湖 & 月牙湖 & 琵琶湖 & 前湖 \\
\hline \multirow[t]{4}{*}{ 蓝藻门 Cyanophyta } & 微囊藻 & Microcystis spp. & & & + & & + & \\
\hline & 束丝藻 & Aphanizomenon spp. & & & & & + & \\
\hline & 色球藻 & Chroococcus spp. & & + & & + & & \\
\hline & 平列藻 & Merismopedia spp. & & & & + & & \\
\hline 绿藻门 Chlorophyta & 卵囊藻 & Oocystis spp. & + & & & & & \\
\hline 硅藻门 Bacillariophyta & 小环藻 & Cyclotella spp. & & + & & + & & \\
\hline 隐藻门 Cryptophyta & 蓝隐藻 & Chroomonas spp. & & & & & & + \\
\hline
\end{tabular}

+表示出现优势种.

\section{3 不同氮、磷营养水平自然水体对铜绿微囊藻和斜生栅藻生长及种间竞争的影响}

以淡水常见蓝藻优势种——铜绿微囊藻和淡水常见绿藻优势种——斜生栅藻为研究对象, 利用南京城 
区不同富营养化程度的水体进行藻类生长潜力试验, 探究不同氮、磷水平水体对两种代表性藻种生长及竞 争的影响. 结果表明, 单一藻种培养时, 铜绿微囊藻仅在清溪、护城河及玄武湖的滤后水中大量生长, 在第 12 天左右达到最大细胞密度, 分别为 $396 \times 10^{4} 、 320 \times 10^{4}$ 和 $202 \times 10^{4} \mathrm{cells} / \mathrm{ml}$ ( 图 1), 达到水华发生时的藻细胞密 度 $\left(10^{6} \mathrm{cell} \mathrm{s} / \mathrm{ml}\right)$; 而琵琶湖、前湖和月牙湖的滤后水均不能促进铜绿微囊藻的生长, 藻种在接种后几天就死 亡了. 斜生栅藻在清溪和护城河水体中能够大量生长, 最大细胞密度分别达到了 $246 \times 10^{4}$ 和 $68 \times 10^{4} \mathrm{cell} / \mathrm{s} / \mathrm{ml}$ (图 1), 而在月牙湖、玄武湖、琵琶湖和前湖滤后水体中也无法很好地生长.
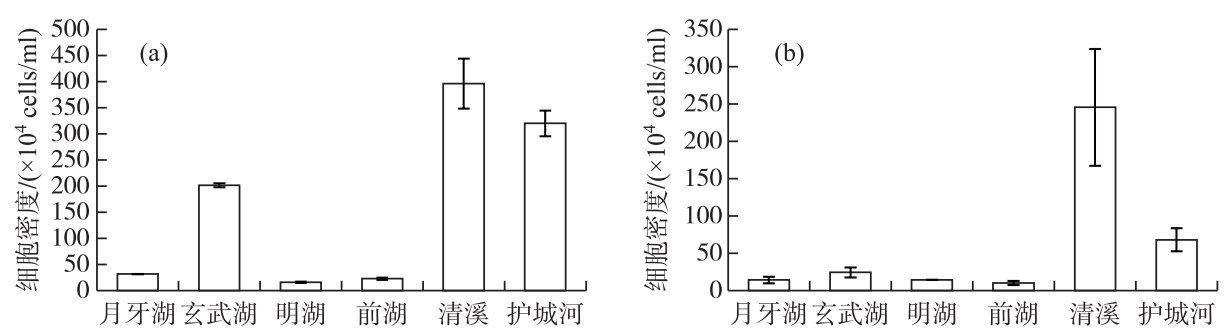

图 1 单种培养时不同水体中铜绿微囊藻 ( a ) 和斜生栅藻 (b) 的最大细胞密度

Fig.1 Maximal cell densities of Microcystis aeruginosa (a) and Scenedesmces obliquus (b) in different water bodies with unialgal cultures

两种藻共培养时, 清溪水体中斜生栅藻占优势, 护城 河和玄武湖水体中铜绿微囊藻占优势, 而其他水体中两种 藻均不能生长 (图 2). 推测可能是由于琵琶湖、前湖和月 牙湖氮、磷浓度低, 不能满足两种藻的生长需求, 而护城河 和玄武湖水体氮、磷浓度能够促进铜绿微囊藻的生长, 但 不能满足斜生栅藻的高氮、磷需求. 清溪水体氮、磷浓度最 高, 极大地刺激了斜生栅藻的生长, 同时由于混合藻中斜 生栅藻对 $\mathrm{NH}_{4}^{+}-\mathrm{N}$ 的耐受能力比铜绿微囊藻强, 清溪水体高 浓度 $\mathrm{NH}_{4}^{+}-\mathrm{N}$ 更有利于斜生栅藻形成优势.

\section{4 氮、磷添加对不同氮、磷营养水平水体中铜绿微囊藻和 斜生栅藻生长的影响}

为探明玄武湖、琵琶湖、前湖和月牙湖水体无法促进 铜绿微囊藻和斜生栅藻生长的原因, 在不同水体中添加了

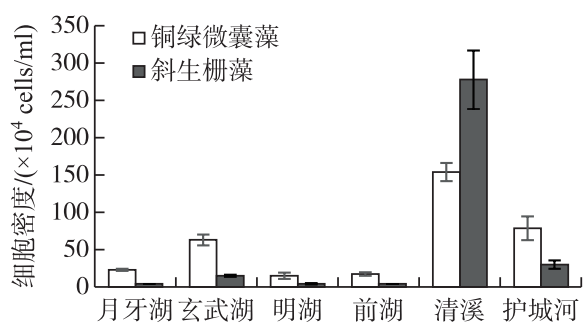

图 2 混合培养中两种藻在不同 水体中的最大细胞密度

Fig.2 Maximal cell densities of Microcystis aeruginosa and Scenedesmces obliquus in different water bodies with multi-species cultures 丰富的氮、磷来培养这两种藻类, 结果如图 3 所示. 玄武湖、琵琶湖、前湖和月牙湖这些营养水平较低的水体 在添加高浓度氮、磷营养盐后, 均能促进铜绿微囊藻和斜生栅藻的生长, 且不同水体的促进效果没有显著差 异, 说明氮、磷浓度低是这些水体无法促进铜绿微囊藻和斜生栅藻的生长的主要原因. 虽然蒸馏水中添加了 相同浓度的氮、磷营养盐, 但对两种藻的生长并没有显著的促进作用, 说明除氮磷外, 自然水体还存在藻类 生长所需的其他营养元素, 随着水体氮、磷浓度的增加, 这些水体具有促进藻类生长的潜力.

\section{3 讨论}

蓝藻水华暴发是淡水水体富营养化的普遍特征 ${ }^{[1]}$. 氮和磷作为藻体构成的重要营养元素, 被认为是浮 游植物生长及水华发生的重要限制因子 ${ }^{[39]}$. 当藻华以蓝藻为优势时, 上行效应比下行效应的影响更大 ${ }^{[2]}$. 野外调查显示, 不同营养水平的水体具有不同的浮游植物优势种, 污染程度较轻的玄武湖和琵琶湖暴发了 以微囊藻为优势的蓝藻水华, 而污染程度较重的清溪河水体则发生了以卵囊藻为优势的绿藻水华. 可见, 不 同的浮游植物有各自独特的营养需求, 在对营养盐的竞争过程中, 营养的供应状况会对浮游植物的群落结 构产生调节作用 ${ }^{[40]}$. 为进一步验证氮、磷污染水平对蓝藻优势形成的影响, 我们利用过滤的自然水体开展 了藻类生长潜力试验. 清溪和护城河的水体能够促进铜绿微囊藻和斜生栅藻的生长, 其中氮、磷浓度最高的 
清溪水体中斜生栅藻占优势, 而氮、磷浓度略低的护城河水体中铜绿微囊藻占优势; 发生微囊藻水华的玄武 湖湖水仅能促进铜绿微囊藻的生长, 而氮、磷浓度很低的月牙湖、琵琶湖和前湖水体均不能促进两种藻的生 长. 由于水体营养成分复杂, 究竟是氮、磷浓度限制了琵琶湖、月牙湖和前湖的藻类繁殖, 还是有其他限制因 子的影响呢? 为此, 我们在琵琶湖、月牙湖、前湖和玄武湖滤后水中添加高浓度氮、磷来培养两种藻类, 发现 4 种水体对铜绿微囊藻和斜生栅藻表现出相似的生长促进作用 (图 3), 可见的确是氮、磷营养水平限制了两 种藻在不同水体中的生长. 向蒸馏水中加人相同浓度氮、磷, 两种藻类均不能正常生长, 这进一步说明不同 污染程度的湖水中均具备藻类生长所需的氮、磷以外的其他元素, 随着氮、磷污染, 像月牙湖和前湖这类低 营养水平湖泊也可能发生藻类水华. 琵琶湖水体氮、磷浓度很低, 利用湖水室内培养的微囊藻无法生长, 但 野外却有大量微囊藻水华发生. 这一方面主要是因为琵琶湖附近当时有一个餐馆, 餐饮排污未经处理直接 进人湖内, 导致产生脉冲式的营养盐补充供藻类生长利用, 另一方面湖泊底泥中内源营养盐在水体营养盐 浓度很低时可以通过浓度梯度扩散向上覆水释放, 从而造成内源补给. 藻类能利用自身生物学特性储存更 多的氮、磷以备缺乏时利用 ${ }^{[14-15]}$. 这说明湖泊蓝藻水华暴发是生态系统综合作用的结果, 外源补给和内部营 养盐的循环均起到重要作用, 仅凭水体的氮、磷浓度无法准确预测水华的发展趋势.
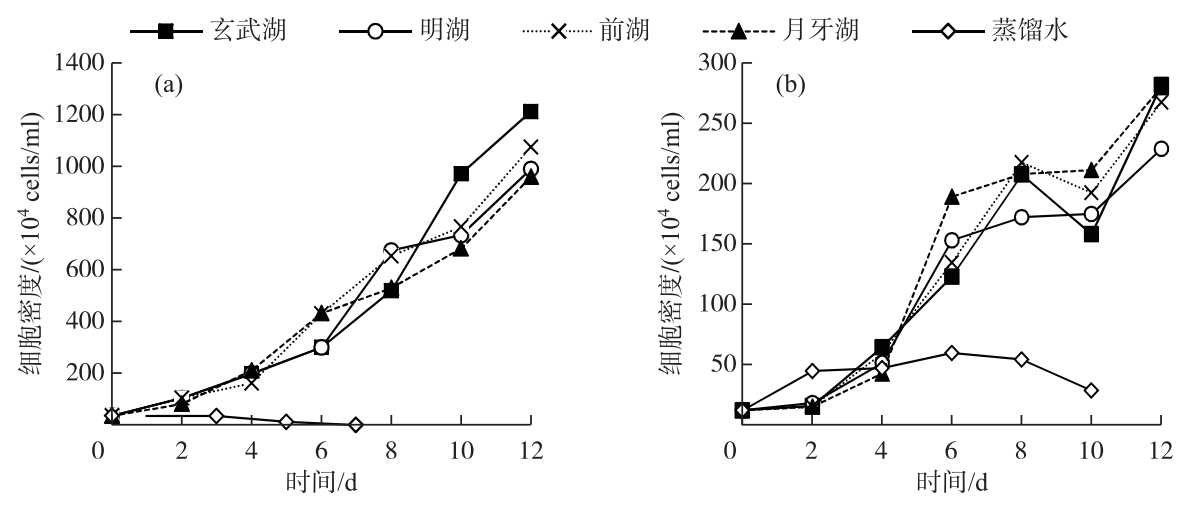

图 3 铜绿微囊藻 ( a) 和斜生㮽藻 (b) 在高浓度氮、磷水体中的生长曲线

Fig. 3 Growth curve of Microcystis aeruginosa (a) and Scenedesmces obliquus (b) with high concentrations of nitrogen and phosphorus

已有研究认为, 铜绿微囊藻属于 $\mathrm{K}$ 策略物种, 当水体氮浓度相对较低时, 易于形成优势, 斜生栅藻属于 $r$ 策略物种, 当水体氮浓度比较高时易于形成优势 ${ }^{[41]}$. 太湖浮游植物优势种长期演化的研究结果显示 ${ }^{[4]}$, 1991-1999 年, 太湖浮游植物生物量每年均在夏季出现峰值, 微囊藻是主要的贡献者, 但 1996 和 1997 年出 现了例外, 转变成绿藻占优势, 分别占到总生物量的 $99 \%$ 和 $94 \%$, 而同时这两年的氮、磷浓度特别高, 说明水 体营养盐供应一旦很充足, 就会出现绿藻占优势的情况. Ma 等 ${ }^{[23]}$ 通过模拟实验也研究了太湖水体添加高浓 度的氮、磷后浮游植物群落的变化, 发现绿藻易于在高浓度氮、磷处理中形成优势. 滇池草海的氮、磷浓度高 于外海, 而水体中绿藻生物量高于蓝藻成为绝对优势澡种, 且绿藻生物量远远高于外海, 表明高氮、磷水体 中绿藻比蓝藻有更强的竞争优势, 致使在超富营养化水体中蓝藻不占优势 ${ }^{[42]}$. 绿藻相对高的生长速率导致 对营养盐的需求也高, 相反, 蓝藻相对低的生长速率导致对营养盐的需求也低 ${ }^{[43]}$. 因此, 在超富营养湖泊生 长快的绿藻在与生长慢的蓝藻竞争时, 容易形成优势 ${ }^{[44]}$. 可见, 蓝藻水华是湖泊富营养化过程中某阶段的 产物, 该阶段很可能是当水体中营养盐达到一定程度, 但又不十分充分的情况下, 其他藻类生长受限制, 蓝 藻因某些生理上的优势, 成为该阶段的优势种; 当水体营养盐继续增加, 达到充分的情况下, 原先具有优势 的蓝藻会逐渐失去竞争优势 ${ }^{[45]}$.

\section{4 结论}

1) 不同营养水平水体浮游植物优势种不同, 氮、磷营养盐浓度偏高的水体绿藻易成为优势种, 氮、磷营 
养盐浓度偏低的水体蓝藻易成为优势种.

2) 蓝藻和绿藻共培养时, 氮、磷浓度偏高的水体对绿藻的促进作用最大, 而氮、磷偏低的水体只能促进 蓝藻生长, 氮、磷浓度没达到富营养水平的水体不能促进两种藻大量生长.

3) 蓝藻水华是湖泊富营养化发展到特定阶段的产物, 水体氮、磷浓度过高或过低均不易产生蓝藻优势.

\section{5 参考文献}

[ 1 ] Paerl HW. Mitigating harmful cyanobacterial blooms in a human-and climatically-impacted world. Life, 2014, 4(4) : 9881012. DOI: 10.3390/life4040988.

[ 2 ] Yang W, Zhu JY, Zhang KX et al. Community dynamics of phytoplankton and related affecting factors in a eutrophicated small pond. Environmental Science, 2015, 36(4) : 1309-1316. DOI: 10.13227/j.hjkx.2015.04.023. [杨文, 朱津永, 张 克金等. 一小型藻华池塘浮游植物群落动态及其影响因子研究. 环境科学, 2015, 36(4) : 1309-1316.]

[ 3 ] Nishikawa T, Tarutani K, Yamamoto T. Nitrate and phosphate uptake kinetics of the harmful diatom Eucampia zodiacus Ehrenberg, a causative organism in the bleaching of aquacultured Porphyra thalli. Harmful Algae, 2009, 8(3) : 513-517. DOI: $10.1016 /$ j.hal.2008.10.006.

[ 4 ] Chen YW, Fan CX, Teubner K et al. Changes of nutrients and phytoplankton chlorophyll-a in a large shallow lake, Taihu, China: an 8-year investigation. Hydrobiologia, 2003, 506-509(1/2/3) : 273-279. DOI: 10.1023/B:HYDR.0000008604. 09751.01 .

[ 5 ] Zhang JY. Metagenomic studies on cyanobacterial blooms in Lake Taihu [Dissertation]. Nanjing: Sourtheast University, 2018. [张军毅. 太湖蓝藻水华的宏基因组学研究 [学位论文]. 南京: 东南大学, 2018.]

[ 6 ] Dokulil MT, Teubner K. Cyanobacterial dominance in lakes. Hydrobiologia, 2000, 438(1/2/3) : 1-12. DOI: 10.1111/j. 1365-2486.20 11.02488.x.

[ 7 ] Zhang YX, Zhang YC, Zhou W et al. Inherent optical properties of typical cyanobacteria in eutrophic lakes. J Lake Sci, 2018, 30(6) : 1681-1692. DOI: 10.18307/2018.0620. [张壹萱, 张玉超, 周雯等. 富营养化湖泊典型水华蓝藻的固 有光学特性. 湖泊科学, $2018, \mathbf{3 0}(6): 1681-1692$.]

[ 8 ] Zhu E, Wang H, Yu DZ et al. Dynamic changes of microcystins and phytoplankton during the cyanobacterial bloom in Lake Erhai in 2013. J Lake Sci, 2015, 27(3): 378-384. DOI: 10.18307/2015.0302. [朱荣, 王欢, 余得昭等. 2013 年 洱海水华期间微囊藻毒素和浮游植物动态变化. 湖泊科学, 2015, 27(3): 378-384.]

[ 9 ] Qin BQ, Xu PZ, Wu QL. Environmental issues of Lake Taihu. Hydrobiologia, 2007, 581 (1) : 3-14. DOI: 10.1007/ s10750-006-05 21-5.

[10] Yang JR, Lv H, Isabwe A et al. Disturbance-induced phytoplankton regime shifts and recovery of cyanobacteria dominance in two subtropical reservoirs. Water Research, 2017, 120: 52-63. DOI: 10.1016/j.watres.2017.04.062.

[11] Lv H, Yang J, Liu L et al. Temperature and nutrients are significant drivers of seasonal shift in phytoplankton community from a drinking water reservoir, subtropical China. Environmental Science and Pollution Research, 2014, 21 : 5917-5928. DOI: $10.1007 / \mathrm{s} 11356-014-2534-3$.

[12] Jiang XY. The influences of nitrogen, temperature and illumination on interactions among Daphania magna, Ceratophyllum demeresum and Microcystis aeruginosa [Dissertation]. Xinxiang: Henan Normal University, 2018. [姜小玉. 氮、温度和光 照对大型溞金鱼藻-铜绿微囊藻三者相互作用的影响研究 [学位论文]. 新乡: 河南师范大学, 2018.]

[13] Jin XC, Zhu ZS, Yang B et al. Effects of temperature on growth, photosynthesis and buoyancy regulation of the cyanobacteria Microcystis flosaquae and Planktothrix mougeotii. Acta Scientiae Circumstantiae, 2008, 28(1) : 50-55. DOI: 10. 13671/j.hjkxxb. 2008.01.018. [ 金相灿, 储昭升, 杨波等. 温度对水华微囊藻及孟氏浮游蓝丝藻生长、光合作用及 浮力变化的影响. 环境科学学报, 2008, 28(1): 50-55.]

[14] Zhou XB, Zhang NH, Zhang Y et al. The temporal and spatial distribution pattern of cyanobacteria and its control method in Taihu Lake. Ecology and Environmental Sciences, 2013, 22(12): 1930-1935. [周笑白, 张宁红, 张咏等. 太湖蓝藻 的时空变化规律及治理方法. 生态环境学报, 2013, 22(12) : 1930-1935.]

[15] Zhou HD, Hu T, Ying TQ et al. Progress on the mechanisms of effects of nutrient salts on cyanobacterial harmful blooms and the salt-based bloom control. Environmental Science and Technology, 2015, 38(11):8-13. [周海东, 胡涛, 应天琪 等. 蓝藻暴发的营养盐作用机制与控制研究进展. 环境科学与技术, 2015, 38(11) : 8-13. 
[16] Zhang XD, Cui LJ, Wang JZ et al. Influence from nitrogen-phosphorus ration ratio on interspecific relationship between Nfixing and non N-fixing cyanobacterias. Water Resources and Hydropower Engineering, 2017, 48(9): 29-34, 83. [张骁 栋, 崔丽娟, 王金枝等. 氮磷比对固氮和非固氮蓝藻种间关系的影响. 水利水电技术, 2017, 48(9): 29-34, 83.]

[17] Lin YJ, He ZL, Yang YG et al. Nitrogen versus phosphorus limitation of phytoplankton growth in Ten Mile Creek, Florida, USA. Hydrobiologia, 2008, 605(1) : 247-258. DOI: 10.1007/s10750-008-9360-x.

[18] Dolman AM, Wiedner C. Predicting phytoplankton biomass and estimating critical N:P ratios with piecewise models that conform to Liebig's law of the minimum. Freshwater Biology, 2015, 60(4) : 686-697. DOI: 10.1111/fwb.12518.

[19] Zhang JY, Zhu BC, Wu ZJ et al. Microcystis panniformis-A newly recorded species of Microcystis in China. J Lake Sci, 2012, 24(4) : 647-650. DOI: 10.18307/2012.0421. [张军毅, 朱冰川, 吴志坚等. 片状微囊藻 ( Microcystis panniformis) 一一中国微囊藻属的一个新记录种. 湖泊科学, 2012, 24(4) : 647-650.]

[20] Downing JA, Watson SB, McCauley E. Predicting cyanobacteria dominance in lakes. Canadian Journal of Fisheries and Aquatic Sciences, 2001, 58(10) : 1905-1908. DOI: 10.1139/cjfas-58-10-1905.

[21] Smith VH. Low nitrogen to phosphorus ratios favor dominance by blue - green algae in lake phytoplankton. Science, 1983, 221: 669-671. DOI: 10.1126/science.221.4611.669.

[22] Xie LQ, Xie P, Li SX et al. The low TN :TP ratio, a cause or a result of Microcystis blooms? Water Research, 2003,37 : 2973-2080. DOI: 10.1016/S0043-1354(02)00532-8.

[23] Ma JR, Qin BQ, Wu P et al. Controlling cyanobacterial blooms by managing nutrient ratio and limitation in a large hypereutrophic lake: Lake Taihu, China. Journal of Environmental Sciences, 2015, 27 (1) : 80-86. DOI: 10.1016/j. jes. 2014.05.042.

[24] Katherine ZF, Moe B, Li XF et al. Cyanobacterial bloom dynamics in Lake Taihu. Journal of Environmental Sciences, 2015, 32(6) : 249-251. DOI: 10.1016/j.jes.2015.04.003.

[25] Liu QG, Chen LQ, Chen Y. Correlation between biomass reduction of silver carp and bighead carp and the occurrence of algal blooms in Lake Qiandaohu. Transactions of Oceanology and Limnology, 2007, (1): 117-124. [刘其根, 陈立侨, 陈勇. 千岛湖水华发生与主要环境因子的相关性分析. 海洋湖沼通报, 2007, (1) : 117-124.]

[26] Xu H, Yang LZ, Mao H et al. Dynamic studies on the effect of phosphorus on the growth of Microcystis aeruginosa and Scendesmus obliquus. Ecology \& Environment, 2006, 15(5): 921-924. [许海, 杨林章, 茅华等. 铜绿微囊藻、斜生栅 藻生长的磷营养动力学特征. 生态环境, 2006, 15(5): 921-924.]

[27] Xu H, Yang LZ, Liu ZP. Dynamics study on the effect of nitrogen on the growth of Microcystis aeruginosa and Scendesmus obliquus. Research of Environmental Sciences, 2008, 21(1): 69-73. [许海, 杨林章, 刘兆普. 铜绿微囊藻和斜生栅藻 生长的氮营养动力学特征. 环境科学研究, 2008, 21(1): 69-73.]

[28] Wan L, Zhu W, Zhao LF. Effect of nitrogen and phosphorus on growth and competition of M. aeruginosa and S. quadricauda. Environmental Science, 2007, 28(6) : 1230-1235. DOI: 10.13227/j.hjkx.2007.06.011. [万蕾, 朱伟, 赵联芳. 氮 磷对微囊藻和栅藻生长及竞争的影响. 环境科学, 2007, 28(6) : 1230-1235.]

[29] Xu H, Qin BQ, Zhu GW. Nutrient limitation of cyanobacterial growth in different regions of Lake Taihu in summer. China Environmental Science, 2012, 32(12): 2230-2236. [许海, 秦伯强, 朱广伟. 太湖不同湖区夏季蓝藻生长的营养盐 限制研究. 中国环境科学, 2012, 32(12): 2230-2236.]

[30 ] Li FK, Zhen JF, Jia ZY et al. Impact of nitrogen and phosphorus on algal growth and kinetics in Haihe River of Tianjin. Chinese Journal of Environmental Engineering, 2017, 11(2) : 959-964. DOI: 10.12030/j.cjee.201509154. [李付宽, 郑 剑锋, 贾泽宇等. 海河干流天津段氮磷对藻类生长的影响及动力学分析. 环境工程学报, 2017, 11(2) : 959-964.]

[31] Yue DM, Li J, Xiao L. Nutrients recovery on the growth of nitrogen and phosphorus starved Microcystis aeruginosa. Environmental Science, 2016, 37(11): 4220-4227. DOI: 10.13227/j.hjkx.201603082. [岳冬梅, 李洁, 肖琳. 营养盐恢复 对氮磷饥饿铜绿微囊藻生长的影响. 环境科学, 2016, 37(11) : 4220-4227.]

[32] Zhang W, Sun J, Nie HT et al. Seasonal and spatial variations of nutrient and the response of phytoplankton in PRE and Adjacent Sea Areas. Acta Ecologica Sinica, 2015, 35(12) : 4034-4044. DOI: 10.5846/stxb201308262158. [张伟, 孙 健, 聂红涛等. 珠江口及毗邻海域营养盐对浮游植物生长的影响. 生态学报, 2015, 35(12): 4034-4044.]

[33] Li XL, Tao L, Mao MZ et al. The effect of the temperature and the N/P concentration on the growth and competition of competition Merismopedia and Scenedesmus. Acta Hydrobiologica Sinica, 2015, 39(6) : 1217-1223. DOI: 10.7541/2015. 158. [李晓莉, 陶玲, 毛梦哲等. 温度和氮磷浓度对平裂藻和栅藻生长及竞争的影响. 水生生物学报, 2015,39 
(6) : 1217-1223.]

[34] Mei ZH, Fang DH, Song YZ et al. Evaluation index system for urban eco-environmental quality of Nanjing. Environmental Science \& Technology, 2005, 28(3) : 81-82, 95. [梅卓华, 方东, 宋永忠等. 南京城市生态环境质量评价指标体系 研究. 环境科学与技术, $2005,28(3): 81-82,95$.

[35] Hu HJ, Wei YX eds. The freshwater algae of china: Systematics, taxonomy and ecology. Beijing: Science Press, 2006. [胡鸿钧, 魏印心. 中国淡水藻类——系统、生态及分类. 北京: 科学出版社, 2006.]

[36] Zhang ZS, Huang XF eds. The research method of freshwater plankton. Beijing: Science Press, 1991: 333-344. [章宗 涉, 黄祥飞. 淡水浮游生物研究方法. 北京: 科学出版社, 1991: 333-344.]

[37] Chen WM, Huang ZS eds. Lake ecosystem observation method. Beijing: China Environmental Science Press, 2004. [ 陈伟 民，黄祥飞. 湖泊生态系统观测方法. 北京: 中国环境科学出版社, 2004.]

[38] Wang MC, Liu XQ, Zhang JH. Evaluate method and classification standard on lake eutrophication. Environmental Monitoring in China, 2002, 18(5): 47-49. [王明翠, 刘雪芹, 张建辉. 湖泊富营养化评价方法及分级标准. 中国环境监 测, $2002,18(5): 47-49$.]

[39] Zhu XY, Wang W, Zeng JN et al. Effects of nitrogen and phosphorus ratios on phytoplankton community structure in winter. Chinese Journal of Applied \& Environmental Biology, 2013, 19(2) : 293-299. DOI: 10.3724/SP.J.1145.2013.00293. [ 朱旭宇, 黄伟, 曾江宁等. 氮磷比对冬季浮游植物群落结构的影响. 应用与环境生物学报, 2013, 19(2): 293-299. ]

[40] Hodgkiss IJ, Lu SH. The effects of nutrients and their ratios on phytoplankton abundance in Junk Bay, Hong Kong. Hydrobiologia, 2004, 512: 215-229.

[41] Xu H, Zhu GW, Qin BQ et al. Influence of nitrogen-phosphorus ratio on dominance of bloom forming cyanobacteria ( Microcystis aeruginosa). China Environmental Science, 2011, 31(10): 1676-1683. [许海, 朱广伟, 秦伯强等. 氮磷比对 水华蓝藻优势形成的影响. 中国环境科学, 2011, 31(10): 1676-1683.]

[42] Hou XL, Yuan CG, Li XP et al. Effect of nitrogen and phosphorus concentrations on the planktonic algae dynamics in Dianchi Lake. Journal of Hydroecology, 2018, 39(1) : 16-22. DOI: 10.15928/j.1674-3075.2018.01.003. [侯秀丽, 苑春 刚, 李学平等. 滇池氮磷浓度变化对蓝、绿、硅藻年际变化的影响. 水生态学杂志, 2018, 39(1) : 16-22.]

[43] Reynolds CS. The response of phytoplankton communities to changing lake environments. Swiss Journal of Hydrology, 1987, 49(2) : 220-236. DOI: 10.1177/030913338901300103.

[44] Jensen JP, Jeppesen E, Olrik K et al. Impact of nutrients and physical factors on the shift from cyanobacterial to chlorophyte dominance in shallow Danish Lakes. Canadian Journal of Fisheries and Aquatic Sciences, 1994, 51(8) : 1682-1699.

[45] Qin BQ. Approaches to mechanisms and control of eutrophication of shallow lakes in the middle and lower reaches of theYangtze River. J Lake Sci, 2002, 14(3) : 193-202. DOI: 10.18307/2002.0301. [秦伯强. 长江中下游浅水湖泊富营养 化发生机制与控制途径初探. 湖泊科学, 2002, 14(3): 193-202.] 